\title{
Generalization of the direct sky component calculation to openings of arbitrary tilt angle
}

\author{
Marilyne Andersen* \\ Building Technology Program, Department of Architecture, Massachusetts Institute of Technology \\ MIT Room 5-418, 77 Massachusetts Avenue, Cambridge MA 02139-4307, USA \\ Tel: (617) 253-7714, Fax: (617) 253-6152, E-mail: mand@mit.edu
}

\begin{abstract}
Amongst the three components of daylight affecting a surface's illumination inside a room, respectively the direct component, due to light flux reaching the surface element directly from the sky, the externally and the internally reflected components, due to light flux reflected on external and internal surfaces, the direct sky component (also called sky factor) is the most significant one. Its estimation must therefore be as accurate as possible when assessing the daylighting performances of a building.

To estimate its value for a given observation surface, analytical methods can be used, based on the luminance distribution of the sky and the window's geometric properties (dimensions and position in regard to the considered surface element). However, such methods have always been restricted to vertical (lateral) and horizontal (zenithal) windows, requiring heavy approximations to be applied whenever a tilted rectangular opening was considered.

In this paper, a generalized method for assessing the sky component is proposed, extending it to rectangular windows of any tilt angle. As a purely analytical approach was found to be inapplicable, it is based on an optimised combination of vertical and horizontal windows situations.

To validate the developed methodology, scale model measurements were performed with a sky simulator for two rectangular openings of varying tilt angle (every $15^{\circ}$ from vertical to horizontal): the experimental results proved to be in very good agreement with the calculation-based approach.
\end{abstract}

Keywords: Direct sky component (sky factor), luminance, illuminance, Daylight Factor, Daylight modelling

\section{Introduction}

Beyond the purely architectural point of view, a planned use of daylight in buildings is essential to improve the visual comfort of their occupants and reduce electricity consumption by achieving a higher autonomy from artificial lighting. Three components affect the value of the illuminance reached on a given surface inside a building: the direct sky component $D_{c}$ (sky factor), due to the light flux penetrating the room and reaching the considered elementary reception surface directly from the sky vault; the externally reflected component $D_{e}$, due to the light flux that underwent at least one reflection on an external surface (close building, ground); the internally reflected component $D_{i}$, due to the light flux that underwent at least one reflection within the room before reaching the reception surface. From these quantities, one can deduce different quantities relevant to determining a room's daylighting performances, such as the Daylight factor $D$, defined as the ratio of the inside and outside illuminances under a CIE overcast sky [CIE 1970], where the outside illuminance relates to a horizontal and unobstructed plane. Of course, when adding up these three components, correction factors are needed to account for the type of glazing, the window frame's exact geometry and the possible wearing or dirt on the different reflection surfaces and glazing.

In practice, the assessment of $D$ can be based on various approaches [Paule 1999]: on scale model measurements under the real or an artificial sky (sky simulator for diffuse light: see e.g. [Schiler 1987, Tregenza 1989, Michel et al. 1997] or more recently[Libby 2003, Darula 2003]), on computer simulations (ray-tracing calculations [Ward and Shakespeare 1998, Erhorn et al. 1997, Mitanchey et al. 1997], use of form factors [LBNL 1994]) or on simplified methods [IEA 2000] (hand calculations, such as the Lumen method [IESNA 1989] or the Split-Flux Method [Hopkinson 1963, BRE 1986]) shown to be the preferred approach by a study conducted in the United Kingdom on

\footnotetext{
* Assistant Professor, PhD, Memberships: IES, ASES/ISES, CIE, CIBSE, SBSE
} 
the use of daylight prediction methods [Aizlewood and Littlefair 1996]. Up to now, the latter were however only applicable to lateral or zenithal openings: the sky component $D_{c}$ for a vertical rectangular opening can indeed be assessed analytically by calculating the light flux emitted by the portion of the sky vault that is seen from the considered elementary surface through the opening [Hopkinson 1963]; an analogous approach can be used to determine $D_{c}$ for a horizontal (zenithal) rectangular opening, explained below. Yet, the existing calculation method becomes inapplicable for tilted openings and therefore calls for heavy approximations when predicting the daylighting performances of a building comprising sheds or inclined roof windows for instance [Paule 1999].

A generalized method for assessing the sky component $D_{c}$ has thus been developed and is presented in this paper, extending it to openings of arbitrary tilt angle. A pure analytical approach was first sought, but proved inapplicable. In consequence, the established methodology aims at determining how several vertical and horizontal openings can be combined most suitably to form a hybrid opening corresponding to a sky vault portion closely matching the one delimited by the tilted window.

The resulting functions were validated against illuminance measurements performed with a sky simulator for two opening sizes, placed at different tilt angles. The close agreement that was achieved between calculated and experimental data allowed to confirm the adequacy and accuracy of the developed method.

\section{Problem statement}

The reference situation for calculating the direct sky component (sky factor) $D_{c}$ assumes the horizontal elementary reception surface (considered as a point and designated by $\mathrm{P}$ ) to be situated along the normal to the window plane drawn from its vertex (bottom corner) [Hopkinson 1963], as shown in Figure 1. For an arbitrary position of $\mathrm{P}$ regarding the window, the latter is split into adjacent sections that can be added or subtracted according to the method described in [Paule 1999,Baker et al. 1993, Bodart 1997, Compagnon 1994], thus recovering the configuration of Figure 1 for each section individually.

Naming $d$ the distance from $\mathrm{P}$ to the window, the latter's dimensions $h$ (height) $\mathrm{x} w$ (width) can be expressed with the polar coordinates $\theta_{0}$ (elevation within the vertical plane containing $\mathrm{P}$ ) and $\varphi_{0}$ (azimuth in window sill plane containing P), illustrated in Figure 1 as angles APB and BPC and respectively equal to $\arctan (h / d) \operatorname{and} \arctan (w / d)$; finally, the arbitrary tilt angle BPO of the window is expressed by $\eta_{0}$ comprised between 0 (vertical opening) and $\pi / 2$ (horizontal opening).

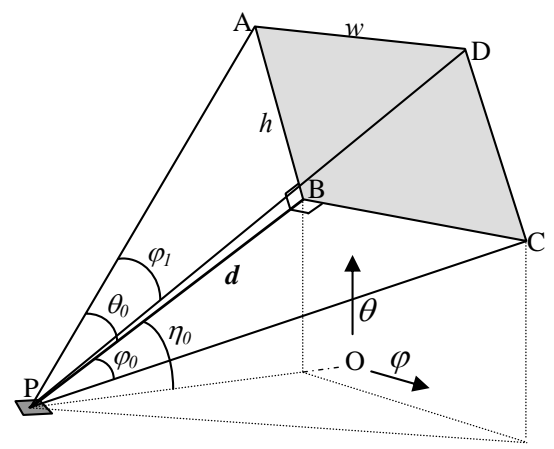

Figure 1 - Rectangular opening of arbitrary tilt angle $\eta_{0}$ : angular coordinates in regard to reception point $\mathrm{P}$.

For any given set of parameters $\theta_{0}, \varphi_{0}$ and $\eta_{0}, D_{c: \eta_{0}, \theta_{0}, \varphi_{0}}$ (also simply noted $D_{c}$ ) is defined as the ratio between the horizontal inside illuminance $E_{P}$ at point $P$ (exclusively lit through a rectangular opening) and the horizontal outside illuminance $E_{h}$ (on an unobstructed plane):

$$
D_{c: \eta_{0}, \theta_{0}, \varphi_{0}}=\frac{E_{P}\left(\eta_{0}, \theta_{0}, \varphi_{0}\right)}{E_{h}}
$$

The two determining parameters are the solid angle corresponding to the sky vault portion seen from point $P$ on one hand, and the sky luminance distribution within this portion on the other hand. For a CIE overcast sky [CIE 1970], the luminance distribution $L(\theta, \varphi)$ depends on the considered position on the canopy of the sky, given by the polar coordinates $\theta$ (elevation) and $\varphi$ (azimuth) defined in Figure 2. It is described by Equation (2), where $L_{z}$ designates the luminance value at the zenith $\left(\theta=\frac{\pi}{2}\right)$ :

$$
L(\theta, \varphi)=L_{z} \frac{1+2 \cdot \sin \theta}{3}
$$

The calculation method was developed and validated for this particular case of luminance distribution $L(\theta$, $\varphi)$ although it remains valid for any luminance variation. The illuminance $E_{P}$ at point $P$ is due to the luminance 
emitted from the sky portion seen from $P$, illustrated in Figure 2. It is calculated by integrating the illuminance $E_{P}(\theta, \varphi)$ over the values taken by $\theta$ and $\varphi$ within this hemisphere portion, $E_{P}(\theta, \varphi)$ being given by Equation (3):

$$
E_{P}(\theta, \varphi)=L(\theta, \varphi) \cdot \sin \theta \cdot \cos \theta \cdot d \theta \cdot d \varphi
$$

The same definition applies to $E_{h}$, where, however, the integration takes place over the whole $2 \pi$ steradian hemisphere as the plane is unobstructed (Equation (4)):

$$
E_{h}=\int_{0}^{2 \pi} d \varphi \int_{0}^{\frac{\pi}{2}} L(\theta, \varphi) \cdot \sin \theta \cdot \cos \theta \cdot d \theta
$$

Replacing $L(\theta, \varphi)$ by its expression in (2), $E_{h}$ is found equal to $\frac{7 \pi}{9} L_{z}$.

As illustrated in Figure 2, PAB intersects the hemisphere along the $\varphi=0$ meridian line. However, the planes PBC and PAD intersect the hemisphere according to curves that are functions of $\varphi$ : curves BC' and A'D' show respective elevations $\eta(\varphi)$ and $\bar{\theta}(\varphi)$ given by Equations (5) and (6) $\left(\eta(0)=\eta_{0} ; \bar{\theta}(0)=\eta_{0}+\theta_{0}\right)$; likewise, the plane PCD intersects the hemisphere according to the curve C'D' of azimuth $\bar{\varphi}(\theta)$ (measured in the horizontal plane) given by Equation (7) $\left(\bar{\varphi}\left(\eta_{0}\right)=\arctan \left(\tan \varphi_{0} / \cos \eta_{0}\right)\right)$.

$$
\begin{gathered}
\eta(\varphi)=\arctan \left(\tan \eta_{0} \cdot \cos \varphi\right) \\
\bar{\theta}(\varphi)=\arctan \left(\tan \left(\theta_{0}+\eta_{0}\right) \cdot \cos \varphi\right) \\
\bar{\varphi}(\theta)=\arctan \left(\frac{\tan \varphi_{0}}{\cos \eta_{0}} \cdot \frac{\cos \theta_{0} \cdot\left(\tan \theta-\tan \eta_{0}\right)+\cos \left(\eta_{0}+\theta_{0}\right) \cdot\left(\tan \left(\eta_{0}+\theta_{0}\right)-\tan \theta\right)}{\cos \left(\eta_{0}+\theta_{0}\right) \cdot\left(\tan \left(\eta_{0}+\theta_{0}\right)-\tan \eta_{0}\right)}\right)
\end{gathered}
$$

Based on the above equations, a general expression can be written for $D_{c}$ :

$$
D_{c: \eta_{0}, \theta_{0}, \varphi_{0}}=\frac{3}{7 \pi} \int_{0}^{\bar{\phi}(\theta)} d \varphi \int_{\eta(\varphi)}^{\bar{\theta}(\varphi)}(1+2 \cdot \sin \theta) \cdot \sin \theta \cdot \cos \theta \cdot d \theta
$$

In the case $\eta_{0}=0$ (vertical opening), $\eta(\varphi)$ and $\bar{\varphi}(\theta)$ are constants, respectively equal to 0 and $\varphi_{0}$, while $\bar{\theta}(\varphi)$ remains a function of $\varphi$. Equation (8) can then be solved by substitution, as detailed in Equations (A.1-A.2) of the appendix, leading to Equation (9) [Hopkinson et al. 1966]:

$$
D_{c: 0, \theta_{0}, \varphi_{0}}=\frac{3}{14 \pi}\left(\varphi_{0}-\varphi_{1} \cdot \cos \theta_{0}\right)+\frac{2}{7 \pi} \arcsin \left(\sin \varphi_{0} \cdot \sin \theta_{0}\right)-\frac{1}{7 \pi}\left(\sin 2 \theta_{0} \cdot \sin \varphi_{1}\right)
$$

where $\varphi_{1}$ is defined in Figures 1 and 2 as angle APD, thus given by Equation (10):

$$
\varphi_{1}=\arctan \left(\tan \varphi_{0} \cdot \cos \theta_{0}\right)
$$

For the general case where $\eta_{0} \geq 0$, however, no analytic solution can be found for (8): the integration limits for $\theta$ are functions of $\varphi$, while the integration limits for $\varphi$ are functions of $\theta$. Likewise would an alternative approach using form factors [Cohen and Wallace 1993] be incompatible with the variation of luminance $L(\theta, \varphi)$ over the hemisphere portion $\left\{\mathrm{A}^{\prime} \mathrm{BC} \mathrm{C}^{\prime} \mathrm{D}\right.$ ' $\}$ delimited by the window, as it is based on pure geometric relationships between two surfaces and is independent of their attributes.

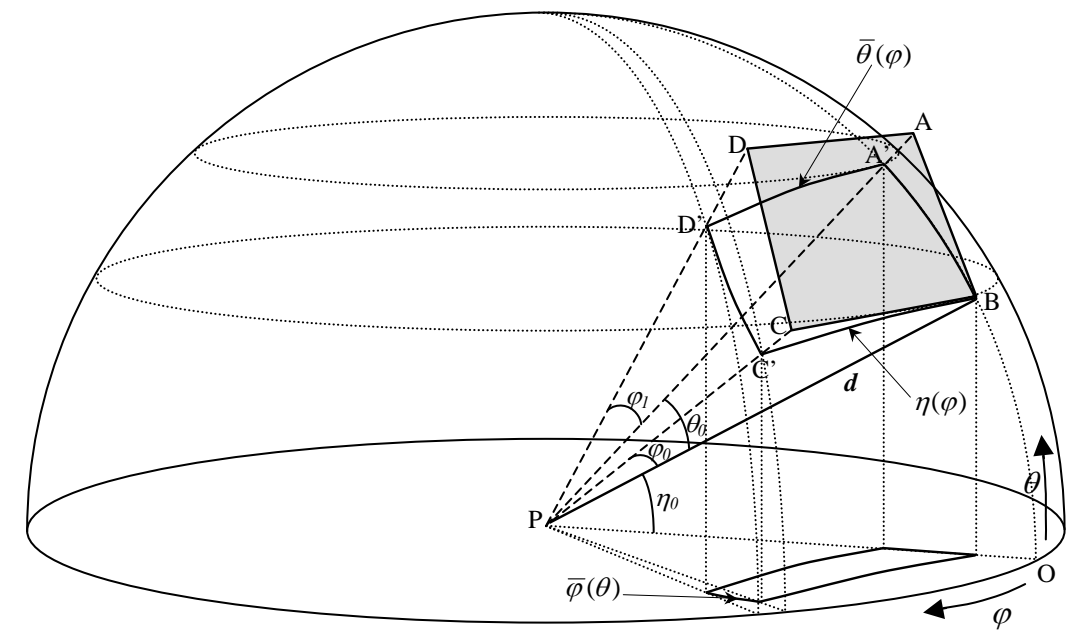

Figure 2 - Hemisphere portion seen from $\mathrm{P}$ through a rectangular opening tilted by an angle $\eta_{0}$.

The same problem actually occurs for horizontal (zenithal) openings: although " $\eta(\varphi)$ " is in this case a constant that equals $\pi / 2, \bar{\theta}(\varphi)$ and $\bar{\varphi}(\theta)$ remain functions of distinct variables, preventing an analytic solution to be found. 
Yet, as illustrated in Figure 3, the hemisphere portion \{A'BC'D'\} delimited by a horizontal opening (the brackets \{\} are used to describe hemisphere parts delimited by the mentioned points) is equivalent to the combination of the two complementary parts $\left\{\mathrm{A}^{\prime} \mathrm{BD}\right.$ ' $\}$ and $\left\{\mathrm{D}^{\prime} \mathrm{BC}\right.$ ' $\}$ of the quarter-hemisphere $\left\{\mathrm{O}_{\mathrm{A}} \mathrm{BO}_{\mathrm{C}}\right\}$ from which portions $\left\{\mathrm{O}_{\mathrm{A}} \mathrm{A}^{\prime} \mathrm{D}^{\prime} \mathrm{O}_{\mathrm{D}}\right\}$ and $\left\{\mathrm{O}_{\mathrm{D}} \mathrm{D}^{\prime} \mathrm{C}^{\prime} \mathrm{O}_{\mathrm{C}}\right\}$ have been subtracted:

$$
D_{c:\left\{A^{\prime} B C^{\prime} D^{\prime}\right\}}=D_{c:\left\{A^{\prime} B D^{\prime}\right\}}+D_{c:\left\{D^{\prime} B C^{\prime}\right\}}=D_{c:\left\{O_{A} B O_{D}\right\}}-D_{c:\left\{O_{A} A^{\prime} D^{\prime} O_{D}\right\}}+D_{c:\left\{O_{D} B O_{C}\right\}}-D_{c:\left\{O_{D} D^{\prime} C^{\prime} O_{C}\right\}}
$$

As $\left\{\mathrm{O}_{A} \mathrm{~A}^{\prime} \mathrm{D}^{\prime} \mathrm{O}_{\mathrm{D}}\right\}$ and $\left\{\mathrm{O}_{\mathrm{D}} \mathrm{D}^{\prime} \mathrm{C}^{\prime} \mathrm{O}_{\mathrm{C}}\right\}$ correspond to hemisphere portions delimited by perpendicular vertical openings, named $V_{A D}$ and $V_{C D}$ in Figure 3, $D_{c:\left\{A^{\prime} B C^{\prime} D^{\prime}\right\}}=D_{c: \pi / 2, \theta_{0}, \varphi_{0}}$ can be expressed as a function of their respective angular dimensions. Applying the substitutions described in the appendix (Equations (A.3-A.4)), it can be converted into Equation (12) ${ }^{\dagger}$ :

$$
\begin{aligned}
D_{c: \pi / 2, \theta_{0}, \varphi_{0}} & =\frac{3}{14 \pi}\left(\arctan \left(\tan \theta_{0} \cdot \cos \varphi_{0}\right) \cdot \sin \varphi_{0}+\arctan \left(\tan \varphi_{0} \cdot \cos \theta_{0}\right) \cdot \sin \theta_{0}\right)+\frac{1}{7} \\
& +\frac{1}{7 \pi}\left(\sin \left(2 \theta_{0}\right) \cdot \sin \left(\arctan \left(\tan \varphi_{0} \cdot \cos \theta_{0}\right)\right)+\sin \left(2 \varphi_{0}\right) \cdot \sin \left(\arctan \left(\tan \theta_{0} \cdot \cos \varphi_{0}\right)\right)\right) \\
& -\frac{2}{7 \pi}\left(\arcsin \left(\sin \left(\arctan \frac{\tan \theta_{0}}{\tan \varphi_{0}}\right) \cdot \cos \varphi_{0}\right)+\arcsin \left(\cos \left(\arctan \frac{\tan \theta_{0}}{\tan \varphi_{0}}\right) \cdot \cos \theta_{0}\right)\right)
\end{aligned}
$$

Vertical and horizontal openings being the only configurations where an exact expression can be determined for $D_{c}$, the method developed to estimate the latter for any value of $\eta_{0}$, detailed below, relies on the most appropriate combination of these two cases to rebuild a hemisphere portion fitting the $\left\{\mathrm{A}^{\prime} \mathrm{BC} \mathrm{C}^{\prime} \mathrm{\}}\right.$ figure as closely as possible.

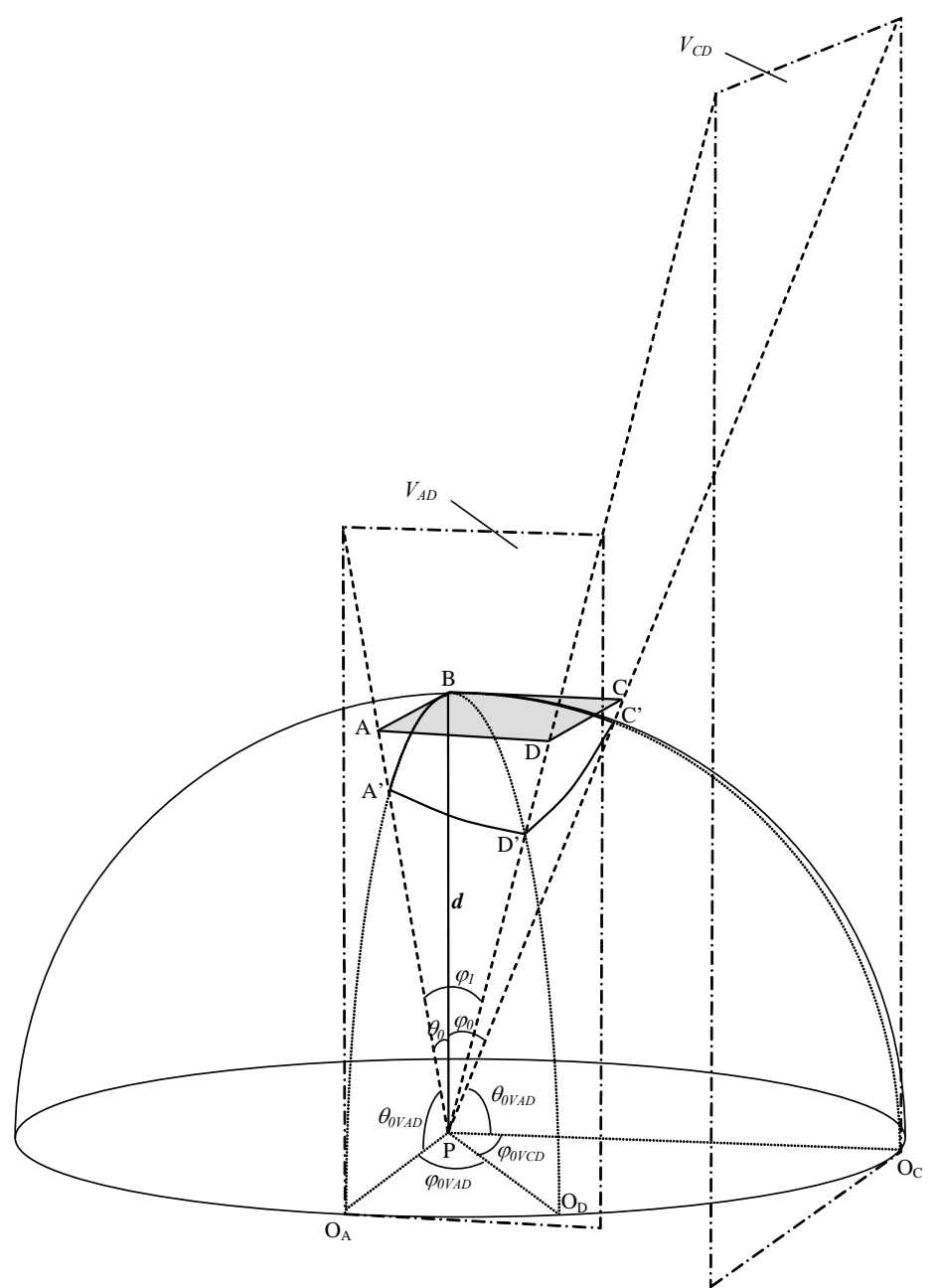

Figure 3 - Combination of two perpendicular vertical openings to determine the hemisphere portion associated to a horizontal opening.

\footnotetext{
${ }^{\dagger}$ Equation (12) slightly differs from the equivalent expressions found in [Baker et al. 1993] and [Bodart 1997], that also disagree with one another; after further investigation, it appears that these differences are only due to miswriting in the two latter publications.
} 


\section{Calculation method}

The calculation method aims at determining what assembly of hemisphere portions corresponding to either vertical or horizontal openings optimally covers the one delimited by a rectangular opening of arbitrary tilt angle $\eta_{0}$. The optimization parameter is the hemisphere area whose associated sky factor cannot be expressed by an equation directly derived from either (9) or (12) : this area must be minimized as the latter has to be assessed through an averaging between the closest vertical or horizontal aperture-based factors.

\subsection{Chosen approach}

Figure 4 illustrates the two ways of approximating the $\left\{\mathrm{A}^{\prime} \mathrm{BC} \mathrm{C}^{\prime} \mathrm{D}^{\prime}\right\}$ hemisphere portion delimited by the tilted opening ABCD. Two pairs of either vertical or horizontal openings are considered: $\left(\mathrm{V}_{\mathrm{ns}}, \mathrm{V}_{\mathrm{nl}}\right),\left(\mathrm{V}_{\mathrm{ws}}, \mathrm{V}_{\mathrm{wl}}\right)$ and $\left(\mathrm{H}_{\mathrm{ns}}\right.$, $\left.\mathrm{H}_{\mathrm{nl}}\right)$, $\left(\mathrm{H}_{\mathrm{ws}}, \mathrm{H}_{\mathrm{wl}}\right)$, where indexes $\mathrm{s}, \mathrm{l}, \mathrm{n}$ and $\mathrm{w}$ stand for short, long, narrow and wide. For each of these pairs, the portion delimited by the short opening is subtracted from the corresponding long one, thus determining areas $\left\{\mathrm{A}^{\prime} \mathrm{BC}^{\prime} \mathrm{D}_{\mathrm{V}}^{\prime}\right\},\left\{\mathrm{A}^{\prime} \mathrm{BC}_{\mathrm{V}} \mathrm{D}^{\prime}\right\},\left\{\mathrm{A}^{\prime} \mathrm{BC}_{\mathrm{H}} \mathrm{D}^{\prime}\right\}$ and $\left\{\mathrm{A}^{\prime} \mathrm{BC}^{\prime} \mathrm{D}_{\mathrm{H}}\right\}$ in the same order. Calculating the average values $D_{c: V}$ and $D_{c: H}$ of the sky components related to $\left\{\mathrm{A}^{\prime} \mathrm{BC}^{\prime} \mathrm{D}_{\mathrm{V}}^{\prime}\right\}$ and $\left\{\mathrm{A}^{\prime} \mathrm{BC}_{\mathrm{V}}^{\prime} \mathrm{D}^{\prime}\right\}$ and to $\left\{\mathrm{A}^{\prime} \mathrm{BC}_{\mathrm{H}}^{\prime} \mathrm{D}^{\prime}\right\}$ and $\left\{\mathrm{A}^{\prime} \mathrm{BC}^{\prime} \mathrm{D}_{\mathrm{H}}{ }_{\mathrm{H}}\right\}$, an approximate value for $D_{c}$ (related to $\left\{\mathrm{A}^{\prime} \mathrm{B} \mathrm{C}^{\prime} \mathrm{D}^{\prime}\right\}$ ) is obtained.

This method assumes the luminance distribution within portions $\left\{\mathrm{C}^{\prime} \mathrm{D}^{\prime} \mathrm{D}_{\mathrm{V}}{ }_{\mathrm{V}}\right\}$ and $\left\{\mathrm{C}_{\mathrm{H}} \mathrm{C}^{\prime} \mathrm{D}^{\prime}\right\}$ to be comparable to the one observed within $\left\{\mathrm{C}^{\prime} \mathrm{C}_{\mathrm{V}}^{\prime} \mathrm{D}^{\prime}\right\}$ and $\left\{\mathrm{C}^{\prime} \mathrm{D}_{\mathrm{H}}^{\prime} \mathrm{D}^{\prime}\right\}$; this tends to be perfectly verified for portions $\left\{\mathrm{C}^{\prime} \mathrm{C}_{\mathrm{V}}^{\prime} \mathrm{D}^{\prime} \mathrm{D}_{\mathrm{V}}\right\}$ and $\left\{\mathrm{C}_{\mathrm{H}}^{\prime} \mathrm{C}^{\prime} \mathrm{D}_{\mathrm{H}}{ }_{\mathrm{H}} \mathrm{D}^{\prime}\right\}$ approaching zero. Hence, to minimize the approximation error, either the vertical or the horizontal opening-based approach is chosen depending on the least hemisphere area represented by portions $\left\{\mathrm{C}^{\prime} \mathrm{C}_{\mathrm{V}} \mathrm{D}^{\prime} \mathrm{D}_{\mathrm{V}}\right\}$ and $\left\{\mathrm{C}_{\mathrm{H}}^{\prime} \mathrm{C}^{\prime} \mathrm{D}_{\mathrm{H}}^{\prime} \mathrm{D}^{\prime}\right\} . D_{c}$ is therefore given by Equation (13), where the expressions of $D_{c: V n l}, D_{c: V n s}, D_{c: V w}, D_{c: V w s}$, $D_{c: H n l}, D_{c: H n s}, D_{c: H w l}$ and $D_{c: H w s}$ are detailed in the appendix (Equations (A.5-A.6)):

$$
D_{c} \cong\left\{\begin{array}{l}
D_{c: V}=1 / 2\left(D_{c: V_{n l}}-D_{c: V_{n s}}+D_{c: V_{w l}}-D_{c: V_{w s}}\right) \text { if }\left\{C^{\prime} C_{V}^{\prime} D^{\prime} D_{V}^{\prime}\right\} \leq\left\{C_{H}^{\prime} C^{\prime} D_{H}^{\prime} D^{\prime}\right\} \\
D_{c: H}=1 / 2\left(D_{c: H_{n l}}-D_{c: H_{n s}}+D_{c: H_{w l}}-D_{c: H_{w s}}\right) \text { if }\left\{C^{\prime} C_{V}^{\prime} D^{\prime} D_{V}^{\prime}\right\}>\left\{C_{H}^{\prime} C^{\prime} D_{H}^{\prime} D^{\prime}\right\}
\end{array}\right.
$$

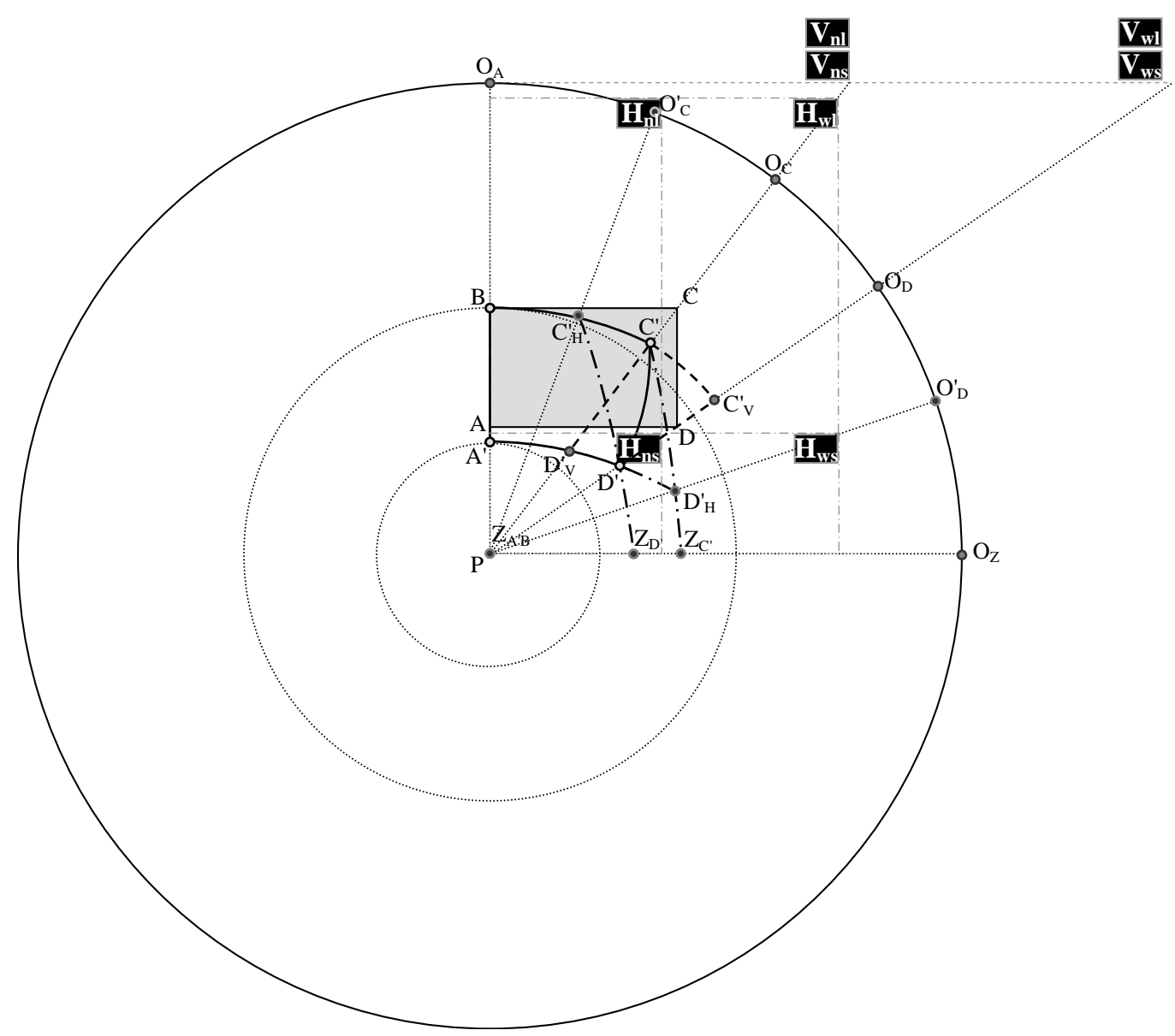

Figure 4 - Vertical view of a rectangular opening of arbitrary tilt angle $\eta_{0}$ and associated hemisphere portion and determination of subtractive pairs of vertical and horizontal openings for the latter's approximation. 


\subsection{Split approximation at large tilt angles}

Whatever the rectangular opening's dimensions, a two-steps treatment is required for tilt angles $\eta_{0}$ larger than $\left(\pi / 2-\theta_{0}\right)$, as the $\left\{\mathrm{A}^{\prime} \mathrm{BC} \mathrm{C}^{\prime}\right\}$ hemisphere portion will be overlapping the zenith $\mathrm{Z}_{\mathrm{A}^{\prime} \mathrm{B}}$, as illustrated in Figure 5 . Defining $\mathrm{Z}_{\mathrm{C}^{\prime} \mathrm{D}^{\prime}}$ as the intersection of $\mathrm{C}^{\prime} \mathrm{D}^{\prime}$ with the meridian line $\mathrm{Z}_{\mathrm{A}^{\prime} \mathrm{B}} \mathrm{O}_{\mathrm{Z}}$, two hemisphere portions $\left\{\mathrm{Z}_{\mathrm{A}^{\prime} \mathrm{B}} \mathrm{BC}^{\prime} \mathrm{Z}_{\mathrm{C}^{\prime} \mathrm{D}^{\prime}}\right\}$ and $\left\{\mathrm{A}^{\prime} \mathrm{Z}_{\mathrm{A}^{\prime} \mathrm{B}} \mathrm{Z}_{\mathrm{C}^{\prime} \mathrm{D}} \mathrm{D}^{\prime}\right\}$ are determined, and analyzed separately.

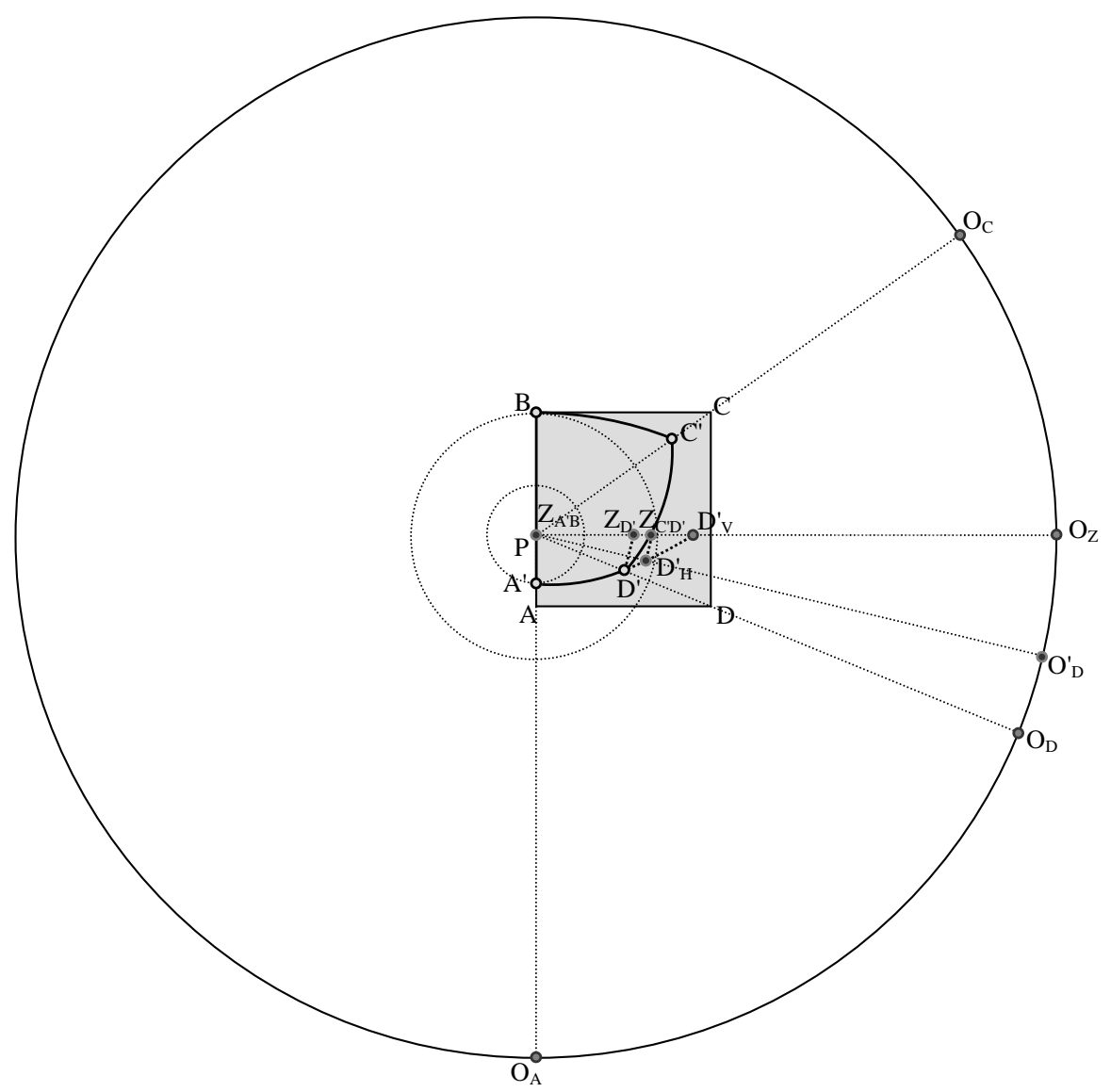

Figure 5 - Vertical view of a rectangular opening of tilt angle $\eta_{0}>\pi / 2-\theta_{0}$ and associated hemisphere portion $\left\{\mathrm{A}^{\prime} \mathrm{BC} \mathrm{C}^{\prime}\right\}$, split into two separately analyzed portions $\left\{\mathrm{A}_{\mathrm{Z}}^{\prime} \mathrm{BC} \mathrm{C}^{\prime} \mathrm{D}_{\mathrm{Z}}\right\}$ and $\left\{\mathrm{A}^{\prime} \mathrm{A}_{\mathrm{Z}}^{\prime} \mathrm{D}_{\mathrm{Z}}^{\prime} \mathrm{D}^{\prime}\right\}$.

$\left\{\mathrm{A}_{\mathrm{Z}} \mathrm{BC}^{\prime} \mathrm{D}_{\mathrm{Z}} \mathrm{z}\right.$ \} corresponds to a rectangular opening tilted by angle $\eta_{0}$ and of elevation and azimuth dimensions $\left(\pi / 2-\eta_{0}\right)$ and $\varphi_{0}$ respectively. The above method can thus be used directly to calculate its associated sky component, whith points $\mathrm{D}_{\mathrm{V}}, \mathrm{D}^{\prime}, \mathrm{D}_{\mathrm{H}}^{\prime}$ and $\mathrm{C}_{\mathrm{V}}^{\prime}$ of Figure 4 appearing on the same meridian line $\mathrm{Z}_{\mathrm{A}^{\prime} \mathrm{B}} \mathrm{O}_{\mathrm{Z}}$. A similar method is applied to calculate the sky component associated to $\left\{\mathrm{A}^{\prime} \mathrm{Z}_{\mathrm{A}^{\prime} \mathrm{B}} \mathrm{Z}_{\mathrm{C}^{\mathrm{D}} \mathrm{D}} \mathrm{D}^{\prime}\right\}$, where Equation (12) is used to express $D_{c: H n l}, D_{c: H n s}, D_{c: H w l}$ and $D_{c: H w s}$ in terms of $\theta_{0}$ and $\varphi_{0}$.

Equation (13) thus becomes:

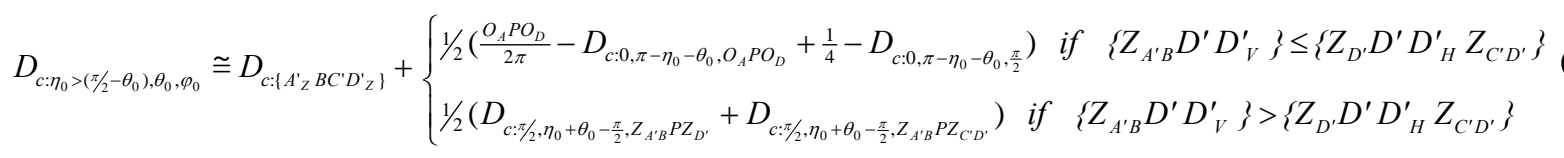

where angles $\mathrm{O}_{\mathrm{A}} \mathrm{PO}_{\mathrm{D}}, \mathrm{Z}_{\mathrm{A}^{\prime} \mathrm{B}} \mathrm{PZ}_{\mathrm{D}^{\prime}}$ and $\mathrm{Z}_{\mathrm{A}^{\prime} \mathrm{B}} \mathrm{PZ}_{\mathrm{C}^{\prime} \mathrm{D}^{\prime}}$ are deduced from trigonometric considerations and given by Equations (15):

$$
\begin{aligned}
& O_{A} P O_{D}=\arctan \left(\frac{\tan \varphi_{0} \cdot \cos \theta_{0}}{\cos \left(\pi-\eta_{0}-\theta_{0}\right)}\right) \\
& Z_{A^{\prime} B} P Z_{D^{\prime}}=\arctan \left(\frac{\tan \varphi_{0} \cdot \cos \theta_{0}}{\cos \left(\eta_{0}+\theta_{0}-\frac{\pi}{2}\right)}\right) \\
& Z_{A^{\prime} B} P Z_{C^{\prime} D^{\prime}}=\arctan \left(\tan \varphi_{0} \cdot \cos \left(\frac{\pi}{2}-\eta_{0}\right)\right)
\end{aligned}
$$




\subsection{Approximation error}

The approximation error can be analyzed from two different points of view: for given angular dimensions $\left(\theta_{0}, \varphi_{0}\right)$ of the opening and a varying tilt angle $\eta_{0}$, the error is proportional to the gap observed on the sky component

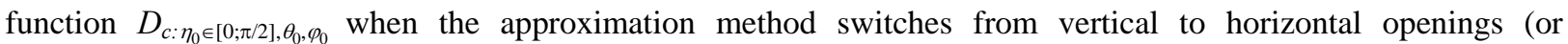
reciprocally); on the other hand, a purely experimental approach can be used to estimate to what extent the established calculation method is accurate, by measuring the sky component for different tilt angles $\eta_{0}$ of a same rectangular opening and comparing the results with the analytical prediction. Both approaches are presented in the two following sections.

\section{Results}

The $D_{c}$ values calculated from the established approximation method are plotted on Figure 6 for a large set of opening configurations, including every combination of $\theta_{0}, \varphi_{0}$ and $\eta_{0}$ angles with $\theta_{0}$ and $\varphi_{0}$ equal to either $20^{\circ}, 45^{\circ}$ or $70^{\circ}$ and $\eta_{0}$ ranging from $0^{\circ}$ to $90^{\circ}$ with a $5^{\circ}$ step.

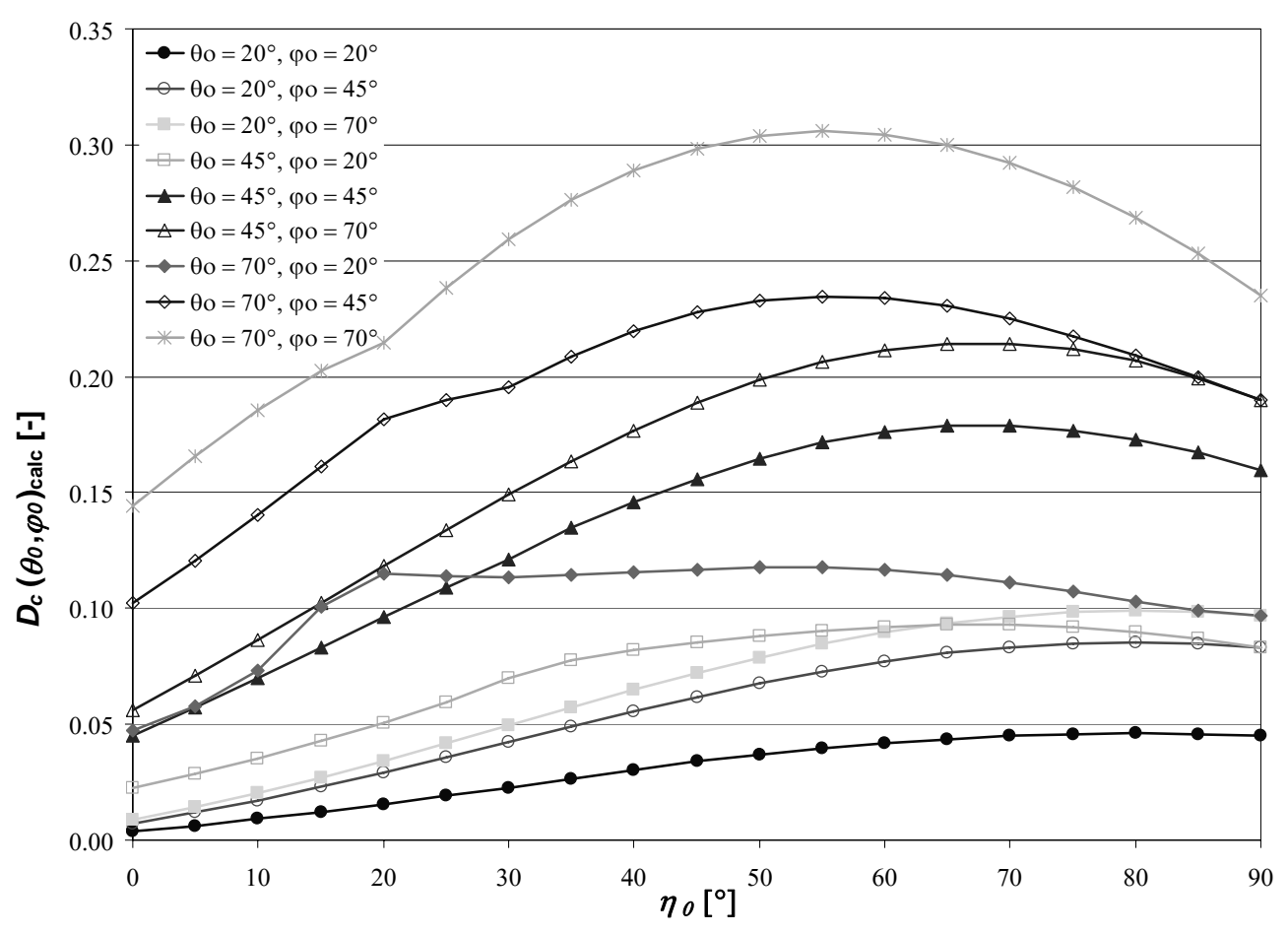

Figure $6-D_{c}$ values deduced from Equations (13) and (14) plotted as functions of $\eta_{0}$ for different angular dimensions $\left(\theta_{0}\right.$, $\left.\varphi_{0}\right)$.

On each $D_{c}$ curve (i.e. for each $\left(\theta_{0}, \varphi_{0}\right)$ pair), the $D_{c}$ values were checked against Equations (9) and (12) for the vertical and horizontal configurations of the opening respectively; it was also verified that the passage from unique hemisphere portion $\left\{\mathrm{A}^{\prime} \mathrm{BC} \mathrm{D}^{\prime}\right\}$ to split method $\left\{\mathrm{A}_{\mathrm{Z}}^{\prime} \mathrm{BC}^{\prime} \mathrm{D}_{\mathrm{Z}}^{\prime}\right\}+\left\{\mathrm{A}^{\prime} \mathrm{Z}_{\mathrm{A}^{\prime} \mathrm{B}} \mathrm{Z}_{\mathrm{C}_{\mathrm{D}} \mathrm{D}} \mathrm{D}^{\prime}\right\}$ did not induce a gap in $D_{c}$ 's variation.

In addition to that, the $\eta_{0}$ angles at which the approximation method switches from the vertical openings'-based alternative to the horizontal one were checked, named $\eta_{\mathrm{OV} / \mathrm{H}}$ whether applied to the complete hemisphere portion $\left\{\mathrm{A}^{\prime} \mathrm{BC} \mathrm{C}^{\prime} \mathrm{D}^{\prime}\right\}$ or to its split parts $\left\{\mathrm{A}_{\mathrm{Z}}^{\prime} \mathrm{BC}^{\prime} \mathrm{D}_{\mathrm{Z}}^{\prime}\right\}$ and $\left\{\mathrm{A}^{\prime} \mathrm{Z}_{\mathrm{A}^{\prime} \mathrm{B}} \mathrm{Z}_{\mathrm{C}^{\prime} \mathrm{D}} \mathrm{D}^{\prime}\right\}$.

These spots are indeed objective indicators of the approximation's accuracy, estimated from the difference between the extrapolated $D_{c}$ variation below and beyond $\eta_{0 \mathrm{~V} / \mathrm{H}}$ and the calculated $D_{c}$ values around $\eta_{0 \mathrm{~V} / \mathrm{H}}$, as summarized in Table 1 for every $\left(\theta_{0}, \varphi_{0}\right)$ pair.

The obtained results show that the assumed relative impact of the approximation method remains below $2 \%$ for most of the opening's configurations, only reaching $7.5 \%$ for an extremely high and thin opening, for which areas $\left\{\mathrm{C}^{\prime} \mathrm{C}_{\mathrm{V}}^{\prime} \mathrm{D}^{\prime} \mathrm{D}_{\mathrm{V}}^{\prime}\right\}$ or $\left\{\mathrm{C}_{\mathrm{H}}^{\prime} \mathrm{C}^{\prime} \mathrm{D}_{\mathrm{H}}^{\prime} \mathrm{D}^{\prime}\right\}$ requiring an interpolation for $D_{c}$ 's estimation are inevitably significant. To assess photometric properties, such errors remain however very reasonable. 


\begin{tabular}{|c|c|c|c|}
\hline$\theta_{0}$ & $\varphi_{0}$ & $\eta_{0 \mathrm{~V} / \mathrm{H}}$ & $\Delta_{\mathrm{rel}} D_{c: \eta_{0}}=\eta_{\mathrm{V}_{\mathrm{VHH}}}, \theta_{0}, \varphi_{0}$ \\
\hline $20^{\circ}$ & $20^{\circ}$ & $40.1^{\circ}$ & $0.8 \%$ \\
$20^{\circ}$ & $45^{\circ}$ & $39.5^{\circ}$ & $0.5 \%$ \\
$20^{\circ}$ & $70^{\circ}$ & $38.8^{\circ}$ & $<0.1 \%$ \\
$45^{\circ}$ & $20^{\circ}$ & $32.1^{\circ}$ & $0.1 \%$ \\
$45^{\circ}$ & $45^{\circ}$ & $32.0^{\circ}$ & $1.8 \%$ \\
$45^{\circ}$ & $70^{\circ}$ & $29.1^{\circ}$ & $0.2 \%$ \\
$70^{\circ}$ & $20^{\circ}$ & $18.7^{\circ}$ & $7.5 \%$ \\
$70^{\circ}$ & $45^{\circ}$ & $26.1^{\circ}$ & $0.4 \%$ \\
$70^{\circ}$ & $70^{\circ}$ & $20.8^{\circ}$ & $0.2 \%$ \\
\hline
\end{tabular}

Table 1 - Estimation of the approximation error by observing the relative differences $\Delta_{\mathrm{rel}} D_{c: \eta_{0}=\eta_{\mathrm{V}_{\mathrm{VH}}}, \theta_{0}, \varphi_{0}}$ between expected $D_{c}$ variation and calculated values for different angular dimensions $\left(\theta_{0}, \varphi_{0}\right)$.

\section{Experimental validation}

\subsection{Experimental set-up}

To validate the established calculation method, a purely experimental approach was chosen, with a physical model shown on Figure 7(a). It consisted of a tiltable rectangular opening of dimensions $w$ x $h=15 \times 10 \mathrm{~cm}$ (also used in a partially obstructed configuration leading to a $10 \times 10 \mathrm{~cm}$ opening) and of a miniature luxmeter manufactured by PRC Krochmann ${ }^{\circledR}$. The latter presents a $6 \mathrm{~mm}$ diameter sensor and was placed at a normal distance $d=20 \mathrm{~cm}$ from the bottom-left corner of the rectangular opening so as to intersect the rotation axis of the latter, as illustrated on Figure 7(a).

To restrict the measured illuminance $E_{P}$ to the sky component only, this model was covered with a black mat paint to avoid any contribution due to internal reflections; in addition to this, opaque and highly absorbing fabrics were fixed around the aperture to prevent light from penetrating the measurement space through other openings, as shown on Figure 7(b).
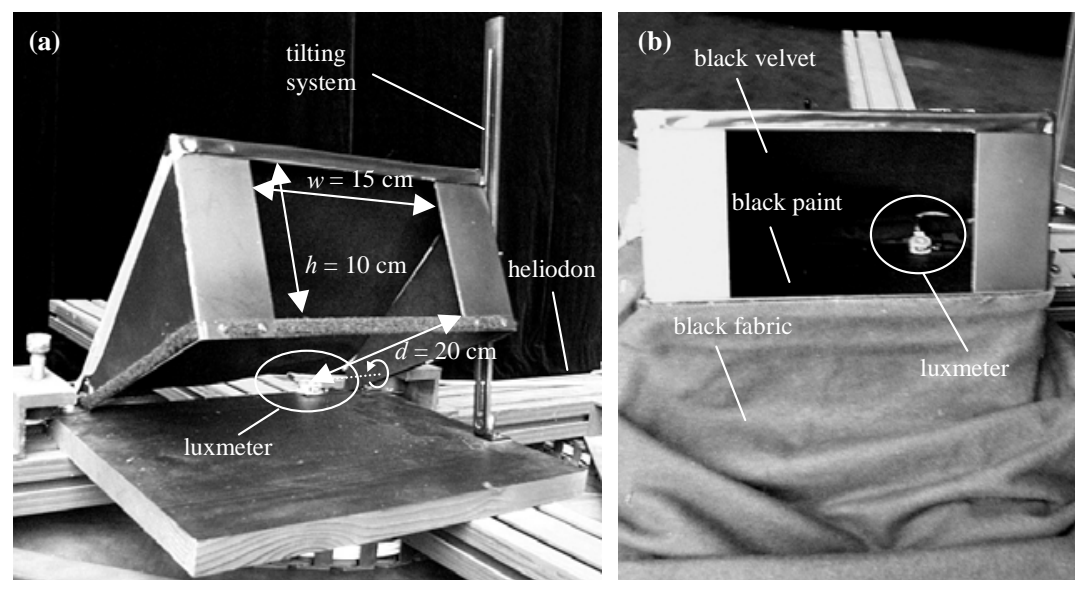

Figure 7 - Experimental model consisting of a tiltable rectangular aperture and a fixed luxmeter (a) protected from parasitic incoming light contributions by opaque and highly absorbing materials (b).

The achieved model was then fixed on a heliodon, as represented on Figure 8(a), for Daylight factor measurements to be performed with a scanning sky simulator for diffuse light [Michel et al. 1997]. This device allows one to reproduce the diffuse component of any type of sky by the means of 145 opalescent disks of $11^{\circ}$ opening angle and of adjustable emitted light flux, shown on the fish-eye view of Figure 8(b); these disks are distributed over the sky vault according to the subdivision of the sky hemisphere for luminance measurements defined by Tregenza [Tregenza 1987] for the International Daylighting Measurement Program (IDMP). For cost, space and more importantly to avoid inter-reflections, only a sixth of the hemisphere is constructed, six positions of the heliodon being thus necessary to achieve a complete measurement, based on the addition of the six partial contributions. 

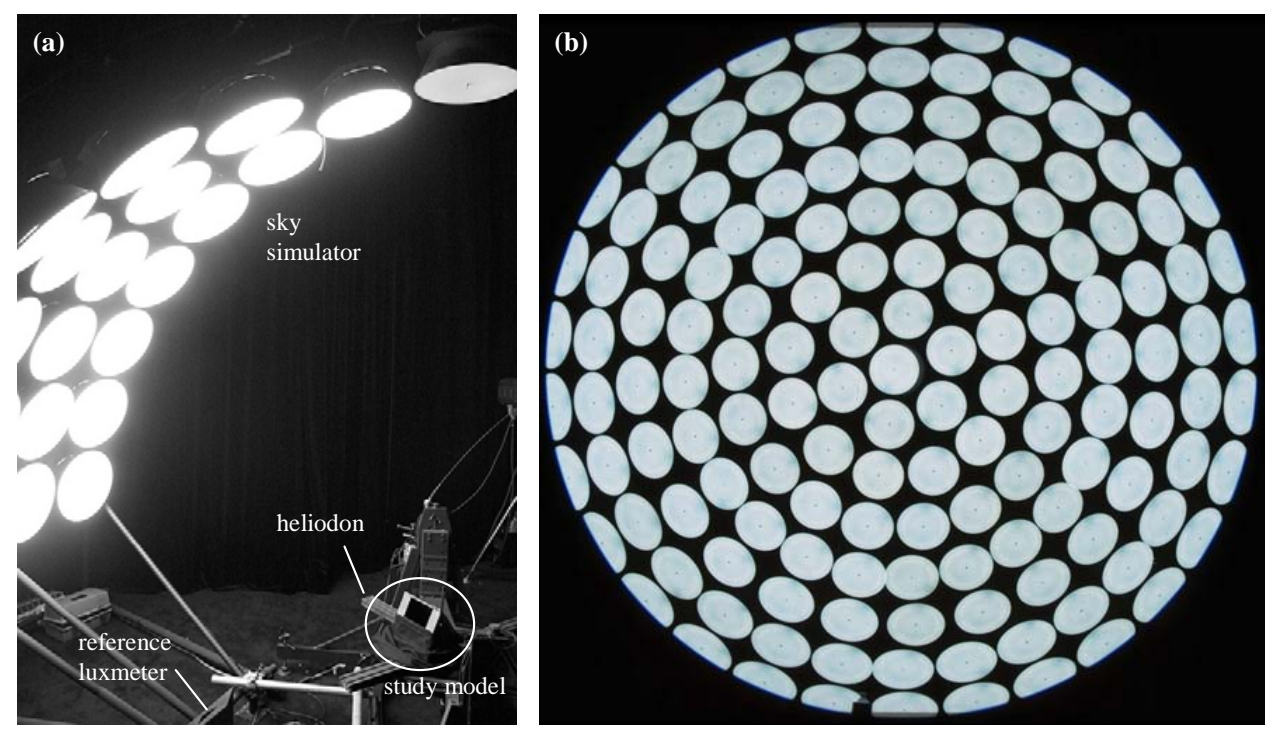

Figure 8 - Scanning sky simulator measurements: (a) Experimental model placed on the heliodon (b) 145 disks to pave the sky hemisphere.

For this particular study, a luminance distribution matching the CIE overcast sky [CIE 1970] was chosen; the Daylight factor - or in this case more specifically the sky component $D_{c}$ - was assessed by calculating the ratio of the illuminance $E_{P}$ measured by the luxmeter placed inside the small dark chamber and the illuminance $E_{h}$ measured by a reference luxmeter of the same kind (pointed out on Figure 8(a)), placed at the bottom of the heliodon and calibrated accordingly.

This procedure was repeated for seven tilt angles of the rectangular opening: $\eta_{0}=0^{\circ}, 15^{\circ}, 30^{\circ}, 45^{\circ}, 60^{\circ}, 75^{\circ}$ and $90^{\circ}$, for each of the two variants of the opening: $w$ x $h=15 \times 10 \mathrm{~cm}$ and $10 \times 10 \mathrm{~cm}$.

\subsection{Data comparison}

For the experimental model, the parameters $d, w$ and $h$ were respectively equal to $20 \mathrm{~cm}$, either 15 or $10 \mathrm{~cm}$ and 10 $\mathrm{cm}$, leading to $\theta_{0}$ and $\varphi_{0}$ values of $26.6^{\circ}$ and either $36.9^{\circ}$ or $26.6^{\circ}$. Analytical estimations of $D_{c}$ were thus made for the fourteen tilt and size configurations based on the above described calculation method, and the experimental $D_{c}$ data plotted against the latter for comparison.

The obtained curves are shown on Figure 9 for each aperture size. Based on the sky simulator's referenced accuracy, $10 \%$ error bars were associated to the measurement results.
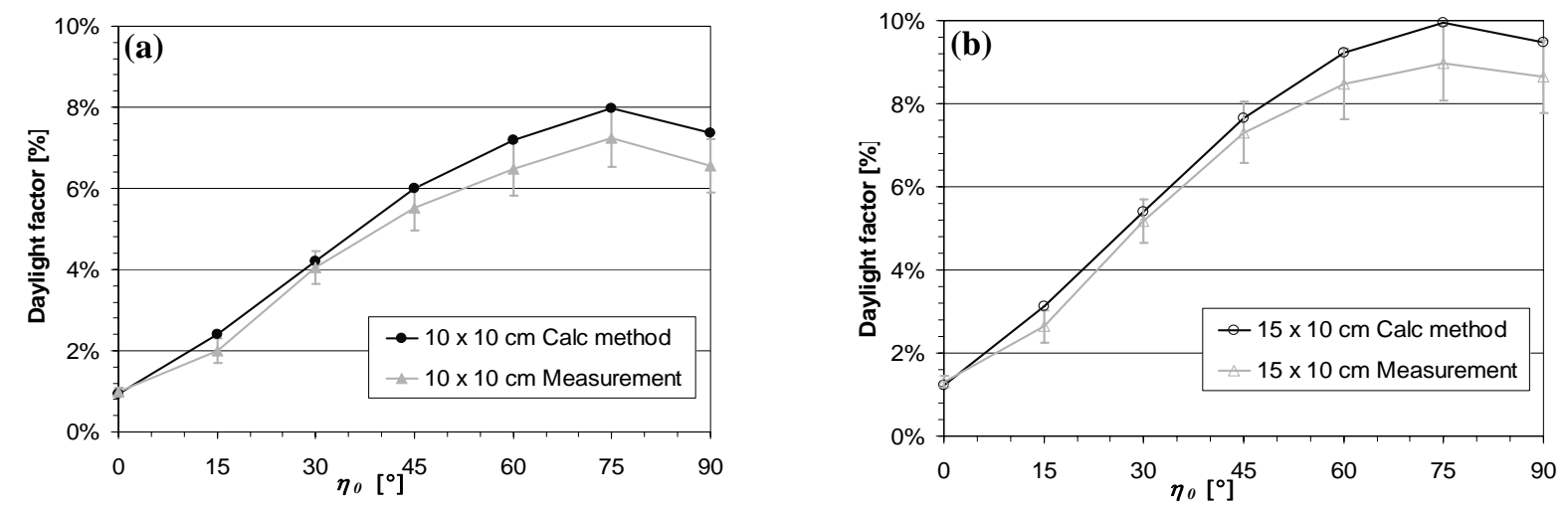

Figure 9 - Comparative study: analytical results validated against measured $D_{c}$ values for varying tilt angles $\eta_{0}\left(\right.$ every $15^{\circ}$ between $0^{\circ}$ and $90^{\circ}$ ) (a) $15 \times 10 \mathrm{~cm}$ aperture (b) $10 \times 10 \mathrm{~cm}$ aperture.

Overall, both graphs show a very close agreement of the experimental and analytical methods, with discrepancies lower than the assumed experimental error. A more detailed analysis outlines that the measured $D_{c}$ values tend to be 
lower than the calculated ones by a slightly increasing interval for growing $\eta_{0}$ values: this is easily explained by the increasing unpaved sky hemisphere proportion (i.e. not comprised within the 145 opalescent disks, which only cover $68 \%$ of the complete vault) when approaching the zenith, as can be observed on Figure $8(\mathrm{~b})$, which disadvantages the aperture's tilt angles facing these sky hemisphere regions (i.e. corresponding to larger $\eta_{0}$ values). Altogether, the remarkable matching of the two datasets allows a positive validation of the established calculation method.

\section{Conclusion}

This paper presents an original calculation method for determining the direct sky component (sky factor) of a rectangular window of any tilt angle. This extension of the existing algorithms, which were up to now restricted to vertical and horizontal openings, will allow one to assess this factor inside a building comprising any configuration of rectangular apertures, typically including sheds, roof windows or tilted atrium openings. It therefore becomes a useful alternative to numerical integration methods, particularly relevant for design programs such as DIAL-Europe [Paule et al. 2003] that are based on simple and analytic methods to make daylight performance predictions. use this in a spreadsheet as you propose. This would be a good clarification of the use of the method. As I mentioned earlier this method has value as a way of checking the results of a more detailed model.

The developed method is based on the representation of the sky hemisphere portion seen from the reception point through the tilted opening by a combination of portions seen through vertical and/or horizontal apertures, as the latter proved to be the only configurations for which an analytical solution can be found for $D_{c}$. The achieved $D_{c}$ values are thus mainly based on a sum of exact analytical solutions except for a small hemisphere part not matching any vertical or horizontal aperture configuration, hence requiring the average value of the closest ones (slightly smaller on one hand and slightly larger on the other) to be calculated and added. To restrict its contribution in the assessment of $D_{c}$, the assembly of vertical and/or horizontal openings leading to a minimal area associated to it is searched for and chosen for evaluating $D_{c}$.

The calculation method's accuracy was first estimated from a strictly analytical point of view by checking whether a gap was observed when the determined combination of vertical openings switched to horizontal ones (or viceversa): the gap proved generally insignificant. On the other hand, it was validated against an experimental approach based on Daylight factor measurements performed with a sky simulator: both datasets fit within a very close range, their discrepancies remaining lower than the assumed experimental error. This brought a strong confidence in the developed calculation method and its applicability to either scale model measurements or building simulation tools calculations. The developed method can be extended to sky luminance distributions other than the CIE overcast variation chosen in this paper (like the Perez' all-weather sky model e.g. [Perez et al. 1993]), as long as the function describing this distribution is integrable.

In a very near future, this method will be implemented in the daylighting design tool DIAL-Europe; this will extend its performances greatly by enabling the Daylight factor distribution and the autonomy from electric lighting to be assessed for rooms including any type of window orientation, non-vertical or horizontal openings appearing nowadays to be far from exceptional configurations.

\section{Acknowledgements}

This work was sponsored by ESTIA (http://www.estia.ch). The author would like to thank Dr. Bernard Paule for having initiated this project, Dr. Magali Bodart and Béatrice de Tilière for their kind help and suggestions in the integrals calculations, Pierre Loesch for his efficiency and conscientiousness in the scale model realization and Anothai Thanachareonkit for her assistance in the Daylight factor measurements. The author is also grateful to the Solar Energy and Building Physics Laboratory (LESO-PB) at the Swiss Federal Institute of Technology (EPFL) for the use of its scanning sky simulator.

\section{References}

Aizlewood, M.E., Littlefair, P.J. 1996. Daylight prediction methods: a survey of their use. In Proceedings of the CIBSE National Lighting Conference: 126-140.

Andersen, M. 2004. Extension of the sky factor calculation method to tilted windows. In Proceedings of IESNA 2004 conference, Tampa, July 25-28.

Baker, N., Fanchiotti, A., Steemers, K. 1993. Daylighting in Architecture - A European Reference Book. London : James \& James. 
Bodart, M. 1997. Eclairage naturel: extension d’une méthode simplifiée aux systèmes zénithaux. Master's thesis, Solar Energy and Building Physics Laboratory, EPFL, Switzerland.

Building Research Establishment. 1986. Estimating daylight in buildings. BRE Digests 309, 310.

Cohen, M.F, Wallace, J.R. 1993. Radiosity and Realistic Image Synthesis. San Diego: Academic Press Professional.

Commission Internationale de l'Eclairage. 1970. Daylight. CIE 16(E. 3.2).

Compagnon, R. 1994. Simulations numériques de systèmes d'éclairage naturel à pénétration latérale. PhD thesis, Ecole Polytechnique Fédérale de Lausanne, Switzerland.

Darula, S. 2003. New measuring method of the diffuse light transmittance. Building Research Journal 51(no. 12): $1-8$.

Erhorn, H., de Boer, J., Dirksmöller, M. 1997. Adeline- An integrated approach to lighting simulation. In Proceedings of IBPSA Building Simulation '97 1: 79-85.

Hopkinson, R.G. 1963. Architectural Physics: Lighting. London: Her Majesty's Stationary Office (HMSO).

Illuminating Engineering Society of North America. 1989. IES Recommended Practice for the Lumen Method of Daylight Calculations, IES RP-23-1989.

International Energy Agency. 2000. Daylight in Buildings - A source book on daylighting systems and components. IEA SHC Task 21 / ECBCS Annex 29, Berkeley: LBNL.

Lawrence Berkeley National Laboratory. 1994. SUPERLITE 2.0 Manual. Berkeley: LBNL.

Libby, B. 2003. Sky Lab - Simulations at Seattle’s Daylighting Lab teach designers just how green their buildings are. The Metropolis Observed. May 2003.

Michel, L., Roecker, C., Scartezzini, J.-L. 1997. Performance of a new scanning sky simulator. Lighting Research and Technology 27(no. 4): 197-207.

Mitanchey, R., Laforgue, P., Fontoynont, M., Marolles, O., Avouac-Bastie, P., Dumortier, D., Duport, J.-M., Kenny, P., Badinier, C., Le Demé, C. 1997. Lighting Calculations on the Internet Using Genelux-Web. In Proceedings of IAEEL Right Light 4 1: 125-130.

Paule, B. 1999. Application de la logique floue à l'aide à la décision en éclairage naturel. PhD thesis, Ecole Polytechnique Fédérale de Lausanne, Switzerland.

Paule, B., Baker, N., Lawton, S., McEvoy, M., Yao, R., de Boer, J., Erhorn, H., Woesner, S., de Groot, E., Zooneveldt, L. Scartezzini, J.-L. 2003. DIAL-Europe European daylighting design tool. In Proceedings International Conference on Sustainable Development in Building and Environment.

Perez, R., Seals, R., Michalsky, J. 1993. All-weather model for sky luminance distribution: preliminary configuration and validation, Solar Energy, 50(3): 235-245.

Schiler, M. 1987. Simulating Daylight with Architectural Models, U.S. Dept. of Energy, University of Southern California.

Tregenza, P.R. 1989. Daylight measurement in models: new type of equipment. Lighting Research and Technology 21(no. 4): 193-194.

Ward Larson, G., Shakespeare, R. 1998. Rendering with Radiance - The Art and Science of Lighting Visualization. San Fransisco: Morgan Kaufmann Publishers, Inc.

Hopkinson, R.G., Petherbridge, P., Longmore, J. 1966. Daylighting. London: Heinemann.

Tregenza, P.R. 1987. Subdivision of the sky hemisphere for luminance measurements. Lighting Research and Technology 19:13-19.

Appendix: Derivations of Equations (9), (12) and (13)

\section{Equation (9)}


In the general expression for $D_{c}$ given by Equation (8), the variable $\theta$ can be substituted for $u$ according to Equation (A.1), which transforms the integration limits into constants:

$$
u(\theta)=\arctan \left(\frac{\tan \theta}{\cos \varphi}\right) \quad \text { i.e. } \quad\left\{\begin{array}{l}
\theta(u)=\arctan (\tan u \cdot \cos \varphi) \\
d \theta=\frac{\cos \varphi}{\cos ^{2} u \cdot\left(1+\tan ^{2} u \cdot \cos ^{2} \varphi\right)} d u
\end{array}\right.
$$

Equation (8) then becomes:

$$
D_{c: 0, \theta_{0}, \varphi_{0}}=\frac{3}{7 \pi}\left(\int_{0}^{\varphi_{0}} d \varphi \int_{0}^{\theta_{0}} \frac{\tan u}{\cos ^{2} u \cdot \cos ^{2} \varphi \cdot\left(\tan ^{2} u+\frac{1}{\cos ^{2} \varphi}\right)} d u+\int_{0}^{\varphi_{0}} d \varphi \int_{0}^{\theta_{0}} \frac{2 \cdot \tan ^{2} u}{\frac{\cos ^{2} u}{\cos ^{3} \varphi} \cdot\left(\tan ^{2} u \cdot \cos ^{2} \varphi+1\right)^{5 / 2}} d u\right)
$$

Applying the adequate trigonometric transformations, one finds out that Equation (A.2) is equivalent to the expression determined in [Hopkinson et al. 1966] for vertical openings, whose solution is given in Equation (9).

\section{Equation (12)}

The perpendicular vertical openings $V_{A D}$ and $V_{C D}$ of Figure 3 are described by their respective angular dimensions $\left(\theta_{O V A D}, \varphi_{O V A D}, \varphi_{I V A D}\right)$ and $\left(\theta_{O V C D}, \varphi_{O V C D}, \varphi_{I V C D}\right)$, defined as in Figure 1. Expressing $D_{c: \pi / 2, \theta_{0}, \varphi_{0}}$ as a function of the latter, one obtains:

$$
\begin{aligned}
D_{c: \pi / 2, \theta_{0}, \varphi_{0}}= & \frac{\varphi_{0 V_{A D}}}{2 \pi}-\frac{3}{14 \pi}\left(\varphi_{0 V_{A D}}-\varphi_{1 V_{A D}} \cdot \cos \theta_{0 V_{A D}}\right)-\frac{2}{7 \pi} \arcsin \left(\sin \varphi_{0 V_{A D}} \cdot \sin \theta_{0 V_{A D}}\right)+\frac{1}{7 \pi}\left(\sin 2 \theta_{0 V_{A D}} \cdot \sin \varphi_{1 V_{A D}}\right) \\
& +\frac{\varphi_{0 V_{C D}}}{2 \pi}-\frac{3}{14 \pi}\left(\varphi_{0 V_{C D}}-\varphi_{1 V_{C D}} \cdot \cos \theta_{0 V_{C D}}\right)-\frac{2}{7 \pi} \arcsin \left(\sin \varphi_{0 V_{C D}} \cdot \sin \theta_{0 V_{C D}}\right)+\frac{1}{7 \pi}\left(\sin 2 \theta_{0 V_{C D}} \cdot \sin \varphi_{1 V_{C D}}\right)
\end{aligned}
$$

Describing the horizontal opening of Figure 3 with parameters $\theta_{0}, \varphi_{0}$ and $d$ as in Figure $1, \theta_{0 V A D}, \varphi_{0 V A D}, \varphi_{I V A D}$, $\theta_{0 V C D}, \varphi_{O V C D}$ and $\varphi_{I V C D}$ can be substituted in (A.3) according to Equations (A.4):

$$
\begin{array}{lll}
\theta_{0 V_{A D}}=\frac{\pi}{2}-\theta_{0} & \varphi_{0 V_{A D}}=\frac{\pi}{2}-\arctan \left(\frac{\tan \theta_{0}}{\tan \varphi_{0}}\right) & \varphi_{1 V_{A D}}=\arctan \left(\tan \varphi_{0} \cdot \cos \theta_{0}\right)=\varphi_{1} \\
\theta_{0 V_{C D}}=\frac{\pi}{2}-\varphi_{0} & \varphi_{0 V_{C D}}=\arctan \left(\frac{\tan \theta_{0}}{\tan \varphi_{0}}\right) & \varphi_{1 V_{C D}}=\arctan \left(\tan \theta_{0} \cdot \cos \varphi_{0}\right)
\end{array}
$$

A final expression for $D_{c: \pi / 2, \theta_{0}, \varphi_{0}}$ is thus obtained, given by Equation (12).

\section{Equation (13)}

Using Equation (9), $D_{c: V n l}, D_{c: V n s}, D_{c: V w l}$ and $D_{c: V w s}$ in Equation (13) can be expressed as functions of the elevation and azimuth angles of the vertical openings they respectively correspond to, shown in Figure 4 . To keep a consistent vertical opening-based format for all $D_{c}^{\prime}$ s, $D_{c: H n l}, D_{c: H n s}, D_{c: H w l}$ and $D_{c: H w s}$ are deduced from Equation (A.3) instead of (12), which altogether leads to Equations (A.5):

$$
\begin{aligned}
& D_{c V_{n l}}=D_{c: 0, \eta_{0}+\theta_{0}, O_{A} P O_{C}} \\
& D_{c V_{n s}}=D_{c: 0, \eta_{0}, O_{A} P O_{C}} \\
& D_{c V_{w l}}=D_{c: 0, \eta_{0}+\theta_{0}, O_{A} P O_{D}} \\
& D_{c V_{w s}}=D_{c: 0, \eta_{0}, O_{A} P O_{D}} \\
& D_{c H_{n l}}=\frac{1}{4}-D_{c: 0, \eta_{0}, O_{A} P O_{C}^{\prime}}-D_{c: 0, Z_{A^{\prime} B} P Z_{D^{\prime}}, \frac{\pi}{2}-O_{A} P O_{C}^{\prime}} \\
& D_{c H_{n s}}=\frac{1}{4}-D_{c: 0, \eta_{0}+\theta_{0}, O_{A} P O_{D}}-D_{c: 0, Z_{A^{\prime} B} P Z_{D^{\prime}}, \frac{\pi}{2}-O_{A} P O_{D}} \\
& D_{c H_{w l}}=\frac{1}{4}-D_{c: 0, \eta_{0}, O_{A} P O_{C}}-D_{c: 0, Z_{A^{\prime} B} P Z_{C^{\prime}}, \frac{\pi}{2}-O_{A} P O_{C}} \\
& D_{c H_{w s}}=\frac{1}{4}-D_{c: 0, \eta_{0}+\theta_{0}, O_{A} P O_{D}^{\prime}}-D_{c: 0, Z_{A^{\prime} B} P Z_{C^{\prime}}, \frac{\pi}{2}-O_{A} P O_{D}^{\prime}}
\end{aligned}
$$


where angles $\mathrm{O}_{\mathrm{A}} \mathrm{PO}_{\mathrm{C}}, \mathrm{O}_{\mathrm{A}} \mathrm{PO}_{\mathrm{D}}, \mathrm{O}_{\mathrm{A}} \mathrm{PO}_{\mathrm{C}}^{\prime}, \mathrm{O}_{\mathrm{A}} \mathrm{PO}_{\mathrm{D}}^{\prime}, \mathrm{Z}_{\mathrm{A}^{\prime} \mathrm{B}} \mathrm{PZ}_{\mathrm{C}^{\prime}}$ and $\mathrm{Z}_{\mathrm{A}^{\prime} \mathrm{B}} \mathrm{PZ}_{\mathrm{D}^{\prime}}$ can be deduced from trigonometric considerations and are given by Equations (A.6):

$$
\begin{aligned}
& O_{A} P O_{C}=\arctan \left(\frac{\tan \varphi_{0}}{\cos \eta_{0}}\right) \\
& O_{A} P O_{D}=\arctan \left(\frac{\tan \varphi_{0} \cdot \cos \theta_{0}}{\cos \left(\eta_{0}+\theta_{0}\right)}\right) \\
& O_{A} P O^{\prime}{ }_{C}=\arctan \left(\frac{\tan \eta_{0} \cdot \cos \theta_{0} \cdot \tan \varphi_{0}}{\sin \left(\eta_{0}+\theta_{0}\right)}\right) \\
& O_{A} P O^{\prime}{ }_{D}=\arctan \left(\frac{\tan \varphi_{0} \cdot \tan \left(\eta_{0}+\theta_{0}\right)}{\sin \eta_{0}}\right) \\
& Z_{A^{\prime} B} P Z_{C^{\prime}}=\arctan \left(\frac{\sin \eta_{0}}{\tan \varphi_{0}}\right) \\
& Z_{A^{\prime} B} P Z_{D^{\prime}}=\arctan \left(\frac{\sin \left(\eta_{0}+\theta_{0}\right)}{\tan \varphi_{0} \cdot \cos \theta_{0}}\right)
\end{aligned}
$$

Equation (13) is hence solved by calculating each of its $D_{c}$ terms using (9), the adequate substitutions of $\theta_{0}, \varphi_{0}$ and $\varphi_{1}$ in (9) being applied according to (A.5) and (A.6). 